\title{
VIOLÊNCIA E CONTROLE SÓCIO-PENAL CONTRA ADOLESCENTES COM PRÁTICAS INFRACIONAIS
}

\author{
Maria Liduína de Oliveira e Silva ${ }^{1}$
}

\section{RESUMO}

Esse artigo aborda a situação dos adolescentes em conflito com a lei, a partir do imbricamento da relação violência e controle sócio-penal, constitutiva no capitalismo contemporâneo e operacionalizada pelo Sistema de Administração da Justiça Juvenil Brasileiro. Aborda também os principais marcos históricos do controle nas legislações de proteção a infância e a adolescência, bem como, reflete criticamente a relação questão social, Estado penitência e judicialização das relações sociais.

PALAVRAS-CHAVE: Adolescentes, Violência, Controle Sócio-Penal e Prática Infracional

\section{1 - INTRODUZINDO O DEBATE}

\section{Pátria, Lugar de Exílio}

Como lobos de súbito Irrompem na planície citadina

Carregados de morte

Seu nome é violência

Trazem na mão mortíferos sinais

E de órbitas vazias

Caminham em silêncio

Envoltos na solidão

Do crime encomendado

Marginam as esquinas

Escondem o rosto sob o aço liso

Dos capacetes

E anônimos ocultos

Pela espessa cortina de ódio e nevoa

Como robôs avançam

A morte engatilhada

Espero o momento de partir agora

Compra-se o ritual

\footnotetext{
${ }^{1}$ Coordenadora e Professora do Curso de Serviço Social da Universidade Federal de São Paulo UNIFESP/Baixada Santista, Vice-Presidente da Associação Brasileira de Ensino e Pesquisa em Serviço Social (ABEPSS) da Região Sul II (São Paulo e Mato Grosso do Sul) e pesquisadora e militante dos direitos das Crianças e Adolescentes.
} 
Uma voz grita viva A liberdade o coro the responde Pontuados de tiros Canalhas temos fome Arranquemos as pedras da calçada Ó meu amor resiste Luis Filipe

Neste artigo, não temos a pretensão de assumir uma discussão mais sólida sobre o controle sócio-penal, expresso na lei nº 8.069 de 1990, denominada Estatuto da Criança e do Adolescente ou simplesmente chamado de ECA e nem de propor mecanismos de intervenção junto ao Sistema de Administração da Justiça Juvenil. Nossa intenção foi, tão somente, apresentar reflexões preliminares feitas a partir de nossos estudos, militância e experiências na área de defesa dos direitos humanos de crianças e de adolescentes, sobretudo, considerando a necessidade de expô-las para ampliar o debate em torno das violências que cercam os adolescentes que cometeram atos infracionais. Nesse sentido, nos propomos a trabalhar a questão dos adolescentes em conflito com a lei penal numa relação inseparável entre violência e controle sóciopenal, analisando este controle como parte constitutiva da violência institucionalizada pelo capitalismo contemporâneo e operacionalizada pelo Sistema de Administração da Justiça Juvenil Brasileiro.

A questão dos adolescentes em conflito com a lei é atual, polêmica, de relevância social, política e profissional, tendo em vista que envolvem aspectos de ordem estrutural, conjuntural, jurídica e social. Porém, apesar da enorme publicização, dos calorosos debates acerca da redução da maioridade penal, da violência juvenil e de numerosos estudos sobre essa temática, ainda, não se conseguiu pautá-la, com centralidade, numa perspectiva crítica e de totalidade, nem na academia, nem nas Organizações Governamentais e Não-Governamentais e nem nos movimentos sociais, 
sobretudo, no movimento da infância e da adolescência. Pois, geralmente, parte-se de experiências localizadas que, muitas vezes, podem ser significativas, mas, esgotam-se nos próprios sujeitos, sem estabelecer nexos com a estrutura do executivo, do judiciário e do legislativo ou mesmo com a própria sociedade capitalista, que gera desigualdade social.

\section{2 - QUESTÃO SOCIAL, ESTADO-PENITÊNCIA E A JUDICIALIZAÇÃO DAS RELAÇÕES SOCIAIS}

No contexto neoliberal, embora, a violência seja um fenômeno presente em toda sociedade capitalista - produto da desigualdade social - suas maiores vítimas letais são justamente os adolescentes e jovens, pobres e negros, e, sobretudo, aqueles que estão em conflito com a lei porque são violentadores e violentados, numa sociedade em que a ausência de políticas públicas faz com que eles respondam também violentamente num ciclo de violências institucional e cotidiana.

A situação dos adolescentes em conflito com a lei se constitui como uma das expressões mais violentas e terminais da questão social que afeta diretamente os direitos humanos desses sujeitos, pois, além deles estarem privados de liberdade também estão privados de direitos. Na base desse ciclo de violências está à questão social que é incrementada pela desigual relação entre capital e trabalho, pelo mercado mundializado, pela flexibilização e terceirização das relações de trabalho, pela desregulamentação das legislações de proteção social e pela reforma do Estado, aliada as políticas de corte dos gastos sociais.

Assim, a questão social se faz visivelmente maior quando as responsabilidades de quem tem, o Estado brasileiro a relega a um grande vácuo de violências estruturais, institucionais e cotidianas. A partir dessas causas, elevado 
número de adolescente, nos dois primeiros decênios de suas vidas, está submetida à ausência de escola, de saúde, de cultura, de esporte, de lazer e expostos às negligências, aos abusos e a falta de dignidade. Gera-se uma grande desigualdade social que se chama abandono, violência, descaso, omissão, punição, responsabilização penal e controle sócio-penal.

As respostas neoliberais são nítidas, não voltam sua atenção para a qualidade de vida das pessoas, para a proteção social e para a emancipação, liberdade e autonomia humana e sim, como nos ensina Batista (2003), para o ambicioso projeto que é da tolerância zero, da xenofobia, do medo, da segurança máxima, da punição e da criminalização das relações sociais e, sobretudo, da responsabilização penal dos adolescentes pobres.

Wacquant (2001) e Batista (2003) expressam que o empreendimento neoliberal destruiu o Estado do Bem Estar, substituindo-o por um Estado penal. A luz dessa ótica está ocorrendo a passagem do Estado Providência para o Estado Penitência e, com isto, a materialização da judicialização das relações sociais. Simples situações da vida cotidiana que, anteriormente eram resolvidas diretamente entre as pessoas, atualmente passam a ser objeto de intervenção judicial - como, por exemplo: os conflitos entre casais, entre vizinhos e entre pessoas; a regulamentação de visita e de guarda dos filhos; a interdição de pessoas idosas; a negociação de aluguéis e de batida de carros - sendo cada vez mais juridicializadas, a partir da lógica do mercado, das relações sociais como mercadorias. Batista chama essa intervenção judicial de criminalização das relações sociais, ocorrendo uma regulação e controle do cotidiano pelo Estado e pelo mercado.

É evidente que os adolescentes infratores estão incluídos nesse ambicioso projeto de criminalização das relações sociais, já que as respostas do Estado penitência 
não têm sido a construção de escolas e sim a construção de prisões, bem como, a institucionalização do 'controle sócio-penal' - regulamentado pelo direito penal juvenil, previsto no ECA - como uma das estratégias de controle da sociedade do controle, do Estado de Direito.

\section{3 - MARCOS HISTÓRICOS DO CONTROLE NAS LEGISLAÇÕES DE PROTEÇÃO À INFÂNCIA E A ADOLESCÊNCIA}

Violências e controle são marcas da trajetória de atenção dispensada pelo Estado aos adolescentes. A história do controle sócio-penal nasceu com as legislações penais dos adultos. Sua gênese foi com o primeiro Código Criminal do Império, em 1830, e depois, foi também sustentada pelo primeiro Código Penal da República, em 1890, sob o enfoque do penalismo indiferenciado, em que criança e adolescente respondiam por processos crimes da mesma forma que os adultos. No entanto, foi com o processo de consolidação da República, a partir do Movimento dos Reformadores que o 'controle sócio-penal' para crianças e adolescentes sofreu severas críticas.

Em 1927, com a aprovação da primeira lei específica de atenção à infância, chamada Código de Menores Mello Mattos é que o 'controle sócio-penal' foi "transformado" no 'controle sócio-penal informal'. O Código de Menores Mello Mattos, não por acaso, não adotou juridicamente o 'controle sócio-penal' dos Códigos Penais e, sim, assumiu nas práticas sócio-jurídicas a intenção do 'controle sócio-penal', por isso, chamamos de 'controle sócio-penal informal'. Em outros termos, o controle sócio-penal foi juridicamente substituído pelo controle social, fundamentado nas práticas assistencialistas e filantrópicas, que também tinham a dimensão sócio-penal.

Diante disso, crianças e adolescentes foram excluídos dos 'processos crimes', das 'garantias processuais' e da responsabilização penal e assumidos tutelarmente pelo 
Estado paternalista. Isto porque se tratava de uma política com ênfase no "humanismo capitalista", que não queria, ideologicamente, "vender" uma imagem do capitalismo como "penalizador de crianças". Preferiu legitimar-se como "Estado-pai", numa perspectiva paternalista e civilizatória, levantando a bandeira da "proteção" e da “educação".

Sob a égide da Ditadura Militar, em 1979, foi aprovado o segundo Código de Menores que manteve a mesma filosofia tutelar do Código Mello Matos. Assim, o sentido do controle social e não sócio-penal de crianças e adolescentes "abandonados" ou "desviantes" continuava a se justificar pelo "comportamento anti-social", pelo "sintoma do desajustamento social" frente a uma ordem militar, que criminalizava as classes consideradas perigosas.

Com o ECA, aprovado em 1990, engendrou-se uma nova mecânica de 'controle' - que não é mais tão claramente dirigida aos pobres como nos dois Códigos de Menores - pois, trata-se do 'controle sócio-penal' formalmente instituído por um conjunto de normativas nacionais e internacionais que estabeleceu um sistema de garantia de direitos. Neste, estão as condições de exigibilidade dos direitos dos adolescentes em conflito com a lei, as bases para o direito penal juvenil e para o sistema de responsabilidade penal juvenil, operacionalizado pelo sistema de administração da justiça juvenil. Dentre esse conjunto de normativas, destacamos que a Convenção Internacional dos Direitos da Criança (1989), nos artigos 37 e 40, definiu as bases jurídicas e as diretrizes de tratamento do delito dos adolescentes, estabelecendo claramente o ato infracional como um ato de natureza criminal e não de natureza antisocial, como nas legislações anteriores.

Com a implantação do sistema garantista e com a adoção do direito penal juvenil, que defende e responsabiliza penalmente o adolescente, o ECA fez um corte 
com a concepção tutelar de controle social ao impor um conjunto de direitos e deveres como, por exemplo, dentre outros: o devido processo legal; o princípio do contraditório; a ampla defesa; a presunção da inocência; a assistência judiciária; a presença dos pais e responsáveis nos procedimentos judiciários; de ser informado das acusações e de não responder; de confrontação de testemunhas; de interposição de recursos; de apelação para autoridades em diferentes instâncias hierárquicas e o hábeas corpus.

Nesse sistema garantista, o adolescente é concebido como cidadão, isto é, como 'sujeito de direitos' e não 'objeto de tutela', o que lhe dá a capacidade jurídica de responder por seus atos (MENDEZ, 1998). Por ser 'sujeito de direito', o adolescente que cometeu um ato infracional responde penalmente pela infração-crime, na medida em que direitos e deveres fazem igualmente parte desse sistema, no contexto do legal controle sócio-penal. Desta forma, podemos dizer que quando foi conveniente para a imagem do capitalismo, excluir adolescentes dos 'direitos' e dos 'deveres' de 'cidadania' assim o fez. Agora, a lógica do Estado de direitos está sendo inclúi-los na 'cidadania', em razão disso, novas regras são montadas com base em um moderno significado de 'inimputabilidade' e de uma cidadania burguesa, em que eles são penalmente responsabilizados e socialmente violentados por um sistema de injustiças que administra violências e arbitrariedades.

Diante disso, os adolescentes "passaram" de um extremo da "criminalização jurídica da pobreza' das legislações menoristas, para "entrarem" no outro extremo, da 'criminologia jurídico penal', de uma legislação cidadã do Estado-penitência. Porém, com o agravante de que, apesar de não ser somente os adolescentes pobres que cometem atos infracionais, são esses os mais violentados e que continuam selecionados para o aprisionamento. Nos extremos dessas trajetórias permanecem a 'violência' e o 'controle 
sócio-penal', que continuam criminalizando a pobreza e julgando que os adolescentes pobres constituem marginais em potencial.

É bem verdade que, tanto o Código de Menores quanto o ECA apresentam continuidades e descontinuidades em suas respectivas épocas, mas, ambas as leis estão a serviço da 'sociedade do controle' de seus tempos, numa perspectiva de modernização conservadora. Na realidade, podemos dizer que já existia nos Códigos de Menores uma intenção de controle sócio-penal de adolescentes autores de ato infracional, mas, somente no ECA, esse tipo de controle foi legalmente instituído com base no direito penal. Em se tratando especificamente do ECA, na apuração do ato infracional, seu paradigma está alicerçado para atuar no campo da defesa da sociedade e na prevenção geral e, para tanto, as redes de proteção da 'sociedade providencia' foram ampliadas, aumentando não somente o controle sócio-penal, mas, sobretudo, o controle social, a partir da ancoragem preventiva da criminalidade para adolescentes empobrecidos.

Assim, o Estado-penitência se encarrega de amedrontar, judicializar e criminalizar as relações sociais, normatizando e aperfeiçoando os instrumentos punitivos de 'controle sócio-penal', com vistas ao macro 'controle social' da 'sociedade de controle' em suas diferentes formas de dominação. Particularmente, o 'controle sócio-penal juvenil' assume uma importante forma de controle da questão social. Como nos ensinou Meszáros, trata-se de um tipo perverso de 'controle', que defende sutil e flexibilizadamente os reais interesses da desigual relação entre trabalho e capital.

\section{4 - CONSIDERAÇÕES FINAIS}

Apontamos, neste artigo, algumas reflexões, indagações e a necessidade de aprofundarmos as concepções norteadoras do ECA, sobretudo, as relacionadas à responsabilidade penal juvenil e ao controle sócio-penal juvenil. Pois, se, por um lado, a 
introdução das categorias jurídicas "sujeito de direitos" e "infração" foi um avanço na conquista e na garantia do sistema de direitos, por outro lado, esse mesmo paradigma regulamentou a responsabilidade penal juntamente com o controle sócio-penal juvenil aos moldes do sistema penal brasileiro, sem, no entanto, responsabilizar o Estado por seus deveres. Nesses termos, não restam dúvidas de que velhas e novas questões se põem nesse debate, das quais destacamos: no ECA permanece a contradição proteção versus penalização? A centralização da categoria jurídica, seus limites e desdobramentos estão imbricados no âmbito da responsabilização penal juvenil? As categorias jurídicas 'sujeito de direito' e ‘infração' são fundantes do controle sóciopenal? O direito penal juvenil, ainda com tantas controvérsias, está suficientemente esclarecido no mundo jurídico e social? Que concepções de mundo, de homem, de mulher, de criança e de adolescentes e de Estado estão fundamentadas no ECA? Por fim, qual o projeto de sociedade é (re) afirmado no ECA?

Essas indagações são centrais para melhor conhecer e operar o Sistema de Administração da Justiça Juvenil e mesmo assim, ainda, não aceitamos o desafio do enfretamento desse diálogo, que é urgente. Não é possível prescindir desse diálogo numa conjuntura que promove falsos debates e assim, a ausência de embates só tende a despolitizar a questão do adolescente penalizado, na medida em que joga para o atraso e retarda a abordagem política, social e jurídica da possível efetividade de um outro sistema de justiça juvenil que possa promover a potencialização da liberdade e dos direitos humanos.

Para concluir, inferimos que o fim da violência começa na luta contra a desigualdade social, pois, o que temos vivenciado é um cenário espetacular de uma alienação geral que arrebenta com os seus iguais. Uma verdadeira barbárie! Pois, a Pátria que deveria ser um lugar seguro de proteção e de pertença, acaba se tornando - 
como diz o poeta Luis Felipe - um lugar de violências, de exílio para os adolescentes. Não basta somente modificar o 'conteúdo' da lei, sem transformar as concepções que a sustentam; não basta fazer a passagem da condição de 'objeto de intervenções judiciais' para 'sujeito de direitos; não basta a execução de inúmeros programas (Organização Governamental ou Organização Não-Governamental), se não existir a formulação de políticas públicas estruturantes; não basta transformar o 'controle sócio-penal informal' em 'controle sócio-penal formal', sem alterar a raiz (natureza) do controle da sociedade de controle. Não podemos minimizar estas reflexões críticas perante as concepções sustentadoras do ECA e sua relação com o Sistema de Administração de (in)Justiça Juvenil, sob pena de estarmos reafirmando o ciclo perverso das instituições punitivas do Estado capitalista, e abrindo mão da potencialidade, da criatividade e da liberdade dos adolescentes. A palavra que eles mais reivindicam é LIBERDADE. Sonham com uma sociedade livre, com espaços possíveis de energias, criações e liberdades. Como sempre diz Passetti (2003) a "liberdade é a alma dos adolescentes", ou então, como expressa o poeta Murilo Mendes, “o vento liberta-se ventando”. Assim, os adolescentes e os jovens libertam-se pelo exercício da liberdade, que está para além do controle sóciopenal.

\begin{abstract}
This article approaches the teenagers' situation in conflict with the law, from the relation between the violence and the social-criminal control, that is one of the characteristic of the contemporary capitalism and also it is executed by the Brazilian Youthful Justice Administration System. This reflection also approaches the principals historical landmarks of the control in the laws that protects the childhood and teenagers, as also, it reflects critically the relation between the social issues, the penance state and the social relations jurisdiction.
\end{abstract}

KEYSWORD: Teenagers, Violence, Social-Criminal Control, Infractional Acts

Revista Serviço Social \& Saúde. UNICAMP Campinas, v. IX, n. 9, Jul. 2010 


\section{REFERÊNCIAS BIBLIOGRÁFICAS}

BARATtA, A. Criminologia Crítica e Crítica do Direito Penal: introdução à sociologia do direito penal. 2 ed. Rio de Janeiro: Instituto Carioca de Criminologia Freitas Bastos, 1999. (Coleção Pensamento Criminológico, 1).

BATISTA, N. Caros Amigos. São Paulo, n. 77, ano VII, p 28-33, 2003.

Introdução crítica ao direito penal brasileiro. Rio de Janeiro: Revan, $8^{\circ}$ edição, novembro de 2002.

BRASIL. Ministério da Saúde. Estatuto da Criança e do Adolescente. Brasília: 1991. Código Penal. Decreto-lei n. 3.914, de 9 de dezembro de 1941. São Paulo:

Rideel Ltda, 1999.

Código de Menores. São Paulo: Forense, 1982.

MARX, K. Crítica da filosofia do direito de Hegel. Tradução de Conceição Jardim e

Eduardo Lúcio Nogueira. 2. ed. Portugal: Editora Presença; Brasil: Livraria Martins Fontes, [s.d].

MENDEZ, E. G. Infância e cidadania na América Latina. Tradução de Ângela Maria Tijiwa. São Paulo: Hucitec/Instituto Airton Senna, 1998.

MÉSZAROS, I. Para além do capital. Campinas: Editora da UNICAMP; São Paulo: Boitempo, 2002.

PASSETTI, E. Anarquismos e sociedade de controle. São Paulo: Cortez, 2003.

WACQUANT, L. As prisões da miséria. Tradução André Telles. Rio de Janeiro: Jorge Zahar, 2001. 